\title{
DOS PUTOS DE PERO DA PONTE: NOTAS PARA A HISTÓRIA DE UMA PALAVRA
}

\section{THE PUTOS OF PERO DA PONTE: REMARKS ON THE HISTORY OF A WORD}

\author{
Arivaldo Sacramento de Souza ${ }^{1}$ \\ Universidade Federal da Bahia
}

\begin{abstract}
À minha mestra Risonete Batista de Souza, por todas as formas que há de ser dileto.

Ao meu mestre Paulo Roberto Sodré, cujas distâncias me ensinam o presente.
\end{abstract}

\begin{abstract}
Resumo: A sátira medieval galego-portuguesa é fonte diversa para compreensão do significado social das relações entre homens. Embora não seja o corpus em que possamos ouvir a voz do "sodomita", é uma vitrine ampla para o entendimento dos discursos contra a sodomia. Nessa perspectiva, tomamos a cantiga de Pero da Ponte, [Eu digo mal com'ome fodimalho] para analisar os sentidos da palavra "puto", única ocorrência no masculino em todos os Cancioneiros. Para isso, acionamos um conjunto de elementos da prática filológica (paratextos, fontes indiretas, análise de obras lexicográficas e de edição) que possibilitaram encontrar alguns traços semânticos que nos ajudaram a entender a mudança de sentido e a polissemia do termo. Dessa investigação, pudemos chegar às seguintes questões: "puto", na ocorrência da cantiga de Pero da Ponte, é hiperônimo para as relações sexuais entre homens (ativo ou passivo); a mudança em direção à ampliação dos sentidos sexuais da palavra "puto" aconteceu desde a Antiguidade e generaliza-se numa dimensão moral na Idade Média; "puto" parece ter mudado por meio da relação entre mocidade e pureza moral, dessa síntese emergiu a coisificação desses corpos também em contextos de prostituição.
\end{abstract}

Palavras-chave: Sátira medieval galego-portuguesa; Puto; Filologia.

1 arisacramento@gmail.com 


\begin{abstract}
Medieval Galician-Portuguese satire (medieval joke poetry) is a diverse source for understanding the social meaning of relationships between men. Although it is not the corpus in which we can hear the "sodomite's" voice, it is a wide showcase for the understanding of speeches against sodomy. In this perspective, we took the song of Pero da Ponte, [Eu digo mal com'ome fodimalho] to analyze the meanings of the word "puto", the only occurrence in the masculine in all Cancioneiros. For this purpose, we used a set of elements of philological practice (paratexts, indirect sources, analysis of lexicographic and editing works) that made it possible to find some semantic features that helped us understand the change of meaning and the polysemy of the term. From this investigation, we were able to reach the following questions: (i) "puto", in the occurrence of the song by Pero da Ponte, is a hyperonym for sexual relations between men (active or passive); (ii) the change towards the expansion of the sexual meanings of the word "puto" happened since Ancient times and is generalized in a moral dimension in the Middle Ages; (iii) "puto" seems to have changed through the relationship between youth and moral purity, from this synthesis the objectification of these bodies in contexts of prostitution also emerged.
\end{abstract}

Keywords: Medieval Galician-Portuguese satire; Puto; Philology.

A história, complexa e plural, de subjetividades consideradas desviantes precisa ser construída a partir de um conjunto de estratégias muito bem traçadas. É sempre a contrapelo; é constantemente recortada; é muito mobilizada por uma rede produzida em escala desafiadora, mas que, ainda assim, desvela horizontes silenciados pelas narrativas hegemônicas. Entretanto, isso não significa que essa história não possa ser contada! Ao contrário, implica observar o grande esforço empreendido para silenciá-la e, nessa fenda, produzir não um movimento contrário - reativo -, mas uma leitura que compreenda que tensão hierarquizadora tornou possível esse silêncio.

Esse silêncio é prenhe de eloquência. A ponto de textos que são considerados exauridos possam servir de itinerário para outras coordenadas de leitura, desde que mudadas as perguntas, desta vez, produzidas de outro espaço, de outra circunstância temporal por múltiplos olhares (KILOMBA, 2019). É assim que podemos dizer que as estratégias mais contemporâneas de produção de saber (feminismos negros, pensamentos decoloniais, pósmodernidades, estudos culturais etc.) não objetivam negar ou apagar nenhum 
corpus com que o Ocidente se vestiu de verdade absoluta; antes, objetiva garimpar que modus operandi privilegiou determinadas posições de leitura e escrita e deixou de reconhecer outras posturas, aqui, chamadas de plurais por serem mobilizadas por pessoas com interesses diversos, o que garante um olhar mais esférico que plano, com personalidades históricas que não representam dicotomias entre bem e mal, por exemplo. Esse movimento também não pode ser considerado anacrônico, pois considera os limites temporais nos quais nos situamos para a leitura do tempo. E, só então, escolhe outros pontos de vista no estudo do texto que não aquele privilegiado pela vertente hegemônica. Por outras palavras, trata-se de compreender uma série de problemas que foram simplificados em nome de uma objetividade na pesquisa, em nome de um paradigma mais generalizador.

Uma vez destacadas essas questões com que sempre nos deparamos na pesquisa histórica acerca das subalternizações, aproximamo-nos dos estudos medievais para pensar um recorte na situação histórica de homens sodomitas, ou melhor, da avaliação social feita por trovadores nas cortes senhoriais ibéricas acerca das relações entre homens. Algumas reflexões a respeito já foram produzidas por nós acerca dessa temática (SACRAMENTO DE SOUZA, 2008), mas, neste texto, recorreremos a uma investigação sobre (parte d)a história da palavra puto no contexto do português medieval, cuja primeira ocorrência documental é no corpus satírico galego-português, numa cantiga de Pero da Ponte, na qual o trovador se refere genericamente a homens "que s'andam fodendo" como putos.

Para essa discussão, recorremos aos estudos críticos acerca do trovadorismo galego-português; em seguida, analisamos os testemunhos da transmissão; depois, apresentamos as controvérsias etimológicas e lexicográficas em torno da palavra em questão; e, por fim, elaboramos uma reflexão cruzando as informações sobre como a investigação filológica da 
palavra pode deslindar perspectivas contemporâneas sobre sujeitos marginalizados historicamente.

\section{UMA CANTIGA DE PERO DA PONTE: A OCORRÊNCIA PUTO}

Os cancioneiros que transmitiram as cantigas satíricas galegoportuguesas revelam um conjunto de cantigas em que personagens são vituperados pelos mais diversos compositores de trovas. Numa classificação temática proposta pela fecunda edição eletrônica de Graça Videira Lopes e outros, Manuel P. Ferreira e Nuno Júdice, de 2011, podemos encontrar 40 ocorrências de cantigas relacionadas ao "sexo entre homens". Nesse universo, destacam-se diversos trovadores como Estêvão da Guarda, Airas Peres Vuitorom, Pero Garcia Burgalês, entre outros. O fato é que em quase todas as cantigas há menção do nome da personagem ou é possível encontrar referência indireta à personagem visada. Para Paulo R. Sodré, que se debruçou sobre o tema da sodomia no contexto trovadoresco,

No conjunto de cantigas sobre sodomitas, 6 conselheiro (Rui Garcia), chanceler (Estevão Eanes), adeantado (Fernan Díaz [Estaturão]), trovador (Pero de Armea), jogral (Bernal de Bonaval, Saco), malado (Álvar Rodríguiz), cavaleiros e anônimos "putos" são visados pela sátira de aproximadamente dezessete trovadores, dos quais Airas Perez Vuitoron (cinco cantigas), Pero da Ponte (três), Pero Garcia Burgalês (quatro), Dom Dinis (três) e Estevão da Guarda (quatro) são os mais prolíficos. (SODRÉ, 2007, p. 124-125)

A leitura arguta de Sodré, ao longo deste trabalho, oferece uma quantificação que merece reconhecimento, entretanto o que queremos nela destacar é o conjunto de cantigas que dizem respeito aos "anônimos 'putos'” que são visados pela sátira. Em nota a essa passagem (8), Sodré refere-se, em consulta a Madeiro (1992, p. 62), a outros nomes pelos quais os trovadores 
satirizam os sodomitas: "Além de 'puto', os sodomitas são referidos ainda como 'fodidos', 'fudidunculos' e 'sodomiticos' [...]".

Duas dessas designações citadas por Sodré, "putos" e "fodidos" estão numa só cantiga de Pero da Ponte em que o travador satiriza personagens anônimos, qual seja: a cantiga [Eu digo mal, com'home fodimalho], transmitida pelo Cancioneiro da Biblioteca Nacional (B 1626) e pelo Cancioneiro da Biblioteca Vaticana (V 1160). A pergunta que queremos colocar é a seguinte: trata-se de uma personagem anônima ou de uma avaliação genérica do trovador a respeito da sodomia? Conseguir responder a isso, a um só tempo, poderá ajudar a traçar os contornos da palavra puto e entender o teor da sátira, isto é, é um jogo de riso ou uma sátira moral?

Ao defendermos o anonimato, estamos dispostos a entender que se trate de uma sátira a algum personagem cuja inferência seja depreensível dentro do contexto e que, de fato, consiste num simples jogo de palavras contextual; caso optemos pelo argumento da generalidade da crítica, não podemos deixar de reconhecer o teor moral que fundamenta o riso e fomenta a criação de mais e mais cantigas que incomodem àqueles visados, portanto, uma postura moral do trovador em reprovação às relações entre homens.

Sodré defende que se trata de anonimato em vários de seus trabalhos (2004; 2007), uma vez que é preciso compreender o contexto e os mecanismos de funcionamento da cena trovadoresca. O pesquisador acredita que não há teor moralista por parte do trovador Pero da Ponte, já que se trata de uma "burla fictícia", "por meio da retórica da acusação e da injúria" e que ela mais estaria relacionada aos aspectos do funcionamento da corte que necessariamente à sodomia em si, isto é, ao fato de um determinado sujeito ser de natureza sodomítica. Pelas próprias palavras de Sodré:

[...] nas cantigas sobre sodomitas, em sua maioria, eles estão ligados ao funcionalismo da corte (cerca de vinte e uma cantigas) e são "acusados" de 
manterem relações com subordinados $(62,73,116,117,127,194,372,381)$, de obstinarem-se sexualmente $(372,378,380)$, de mudarem os papéis - de passivo para ativo $(81,104,342)$, de serem cruéis nas relações (75), de agirem com hipocrisia $(168,365)$, de desejarem se casar com homem (80) ou de contraírem doenças $(131,404,424)$ (SODRÉ, 2007, p. 129).

Em muitas dessas cantigas, as acusações de sodomia são para acusar determinados sujeitos que estão em posição administrativa e/ou jurídica, tal qual ainda hoje podemos ver nas diversas situações do dia-a-dia em que o simples descontentamento de alguém pode ser suficiente para que o outro que incomoda seja chamado de "viado", "filho da puta" etc. Nesses casos, tal como parece assemelhar-se ao argumento de Sodré, o objetivo é o gracejo, a ofensa e o meio utilizado para isso é que é a inferência, suposição de uma relação sexual com outro homem, fato que é considerado humilhante e de rebaixamento. Mais à frente, ele complementa acerca da sátira de Pero da Ponte:

Nesse sentido, Ponte, assim como seus presumíveis contemporâneos, não parece condenar os sodomitas em si, mas jogar ou brincar com o tema - ou, mais precisamente, tópico - ao que tudo indica menos proscrito no Medievo do que na época da produção dos críticos sobre as cantigas sodomitas (SODRÉ, 2007, p. 130)

Sodré ainda nos é muito estratégico ao considerar, lendo Madeiro (1992, p. 38), que muitas dessas invectivas perdem seu efeito danoso quando o sujeito alvejado participa da cena e interage, esvaziando, pois, o efeito de violência. Se o alvejado está de acordo com o jogo que se estabelece, o que acontece é uma "violência que não desonra", trata-se de um jogo nos quais os participantes estão implicados, como é o caso das cantigas de Pero de Armea e Pero d'Ambroa, em que jogam com os elementos socialmente reconhecidos como femininos (cosméticos de maquiagem) na caracterização de um corpo masculino para a burla. 
Haveria, pois, duas coisas a considerar. Em primeiro plano, esse mecanismo pertenceria às diversas formas de sociabilidade nas cortes senhoriais da poesia trovadoresca. Em segundo plano, não podemos deixar de considerar que essa forma de mobilização social bebe na reprovação moral da sodomia, caso contrário mesmo o pacto cordial da ofensa não poderia funcionar. Essa crítica que não podemos deixar de fazer a essa argumentação diz respeito à eleição do tema. Isso porque, se, de fato, a questão é mesmo jogar com a ofensa que não desonra, nenhum trovador escolheria um tema, ou como prefere Sodré, um “tópico” (2007, p. 132), que não tivesse socialmente o poder de depreciar. Assim, essa sátira está regida sob um imaginário que reconhece a relação sexual entre homens como um mecanismo de rebaixamento de conduta moral. Como tópica, um lugar-comum retoricamente falando, como já disse nosso mestre, a sodomia pode ser dirigida a qualquer que se queira rebaixar, por isso, nesses corpora satíricos, muitas vezes a tópica da sodomia está ligada à sátira que vai usar os elementos da cor da pele como elemento de depreciação contra os mouros.

Desse modo, podemos ver cruzados, numa só cantiga de burla sodomítica, (i) o discurso misógino presente na imagem de que o alvejado quer se passa por mulher, adotando uma posição contrária à própria natureza, i. e., a passividade; (ii) a homofobia ${ }^{2}$, ou seja, um discurso de reprovação que compreende o sexo entre homens como comportamento risível.

Outras posições, as mais antigas por sinal, podem ser ilustradas entre os editores críticos da sátira trovadoresca de Lapa (1995) e Lopes (2011-). Um mapeamento das propostas de interpretação foi feito por Sodré (2004; 2007).

\footnotetext{
2 É preciso guardar as devidas proporções do uso desse termo para o período medieval. Embora a gente não possa falar em rejeição ao sujeito homossexual, cuja identidade parece estar reconhecida socialmente a partir da invenção patológica da clínica médica, segundo Foucault (1988), não podemos deixar de reconhecer que o caráter risível traduz a avaliação social implicada na condenação das relações que são contra a natureza ("contra natura" e "coftũbre [não] natural"), como define a legislação do período (AFONSO X, 2001).
} 
Num resumo mais apressado, identificamos que a ideia mais comum é a de que a sátira de tópica sodomítica tem um teor moral, de exortação dos comportamentos. Contra isso, e com base nos argumentos de Sodré, devemos dizer que essa tese está baseada numa argumentação mais legislativa, atenta a Las Siete Partidas, de Afonso X, ou pode estar ligada a interpretações que confiam mais no tom uníssono que o discurso hegemônico quer naturalizar do que nas tensões e nas disputas de sentido que a irrupção dele provoca, no complexo jogo de dominação. Por isso, essa postura mais plana, deixa de considerar negociações e arestas que se recusam à conclusão categórica.

Nesse sentido, acreditamos que, ao entender a estrutura da cantiga e as relações semânticas entre os versos existentes, poderemos seguir afirmando que se trata, em primeiro plano, de um jogo de desonras entre homens e, em segundo plano, que ele só tem possibilidade de existir dentro de um regime social em que a relação sexual entre homens é visto como pecado contra a natureza, um costume não natural.

Para isso, utilizaremos o texto crítico estabelecido por Videira Lopes que não se difere do de Rodrigues Lapa (1970), a não ser nos mecanismos paratextuais, tais como anotações críticas, glossário, notas editoriais e na possibilidade de consulta aos fac-símiles dos Cancioneiros. Eis o texto:

Pero da Ponte

Eu digo mal, com'home fodimalho, quanto mais posso daquestes fodidos e trob'a eles e a seus maridos; e um deles mi pôs mui grand'espanto: topou comig'e sobraçou o manto e quis em mi achantar o caralho.

Ando-lhes fazendo cobras e sões quanto mais poss', e and'escarnecendo daquestes putos que s'andam fodendo; e um deles de noit[e] asseitou-me 
e quis-me dar do caralh'[e] errou-me

e lançou, depós mim, os colhões. (LOPES, 2011-)

Essa cantiga é bastante importante a nosso ver no rol das cantigas que satirizam a sodomia. E o argumento que queremos defender vem da configuração do Cancioneiro da Biblioteca Nacional, especialmente das rubricas que organizam o leitor nas relações tanto no que diz respeito às autorias/atribuições, quanto às relações intertextuais decididamente existentes. No caso de [Eu digo mal, com'home fodimalho,], precisamos reconhecer que não há nenhuma rubrica no cancioneiro B que relacione essa cantiga a outro trovador, a outro personagem, ou a outra cantiga. Tal situação é bastante diferente da que acontece com as cantigas que já trazem o nome da personagem alvejada em seus versos e daquelas que a rubrica aponta a relação, como é o caso das duas cantigas em que vemos Pero Garcia de Ambroa aproveita a deixa de outra cantiga de Pero d'Armea. Nesse caso, a rubrica indica a relação: "Esta outra cantiga fez Pero d'Ambroa a Pero d'Armea por estoutra de cima que fezera". Como essa, há inúmeras; todas legadas pelo Cancioneiro pelo Biblioteca Nacional, "manuscrito" mais bem cuidado da tradição satírica galegoportuguesa.

Mas, voltando à cantiga, acreditamos que a estrutura da cantiga de Pero da Ponte ajuda-nos numa proposta conciliatória, fruto da interpretação da dinâmica dos versos. É uma cantiga sem refrão, composta por duas estrofes de seis versos. Tanto na primeira, quanto na segunda, há uma divisão entre os sextetos, isto é, os três primeiros versos trazem o que parece ser uma cena reflexiva do trovador que fala em primeira pessoa e reivindica uma posição "fodimalha", viril, de quem pratica o costume natural e que, portanto, pode dizer sobre o mundo. Nos tercetos finais, o texto desdobra-se numa direção mais narrativa, em que o trovador relata que "um deles" tentou assediá-lo, 
"sobraçando o manto" (arregaçando, levantando as vestes) e, depois, “asseitando-o" (espreitando-o, encurralando-o).

Lendo essas estrofes em paralelo, chegamos à conclusão de que não é possível decidir entre a possibilidade de o texto ter sido dirigido a anônimos (na opção arguta de Sodré) ou de ele ter sido escrito num tom de reprovação moral aos sodomitas (conforme editores como Lapa e Lopes). Numa posição privilegiada, de quem pôde reconhecer a tese e antítese, defendemos que os três primeiros tercetos trazem a dimensão moral, o embasamento que faz com que o trovador diga desse lugar de "fodimalho", e que os tercetos finais, por sua factualidade narrativa, são dirigidos a anônimos, em um clima de delação anônima ou de referência indireta. Vale ressaltar que o elemento de transição entre os tercetos iniciais e finais de cada estrofe está materializado por "e um deles", excerto que se repete nas duas estrofes e que cumpre função de transição entre a avaliação moral geral, na qual as marcas de plural atestam a generalidade ("eles", "fodidos", "maridos",/ "lhes", "putos"), e o caso particular a ser narrado, em que as flexões de número estão todas no singular.

\section{3 "DAQUESTES PUTOS QUE S'ANDAM FODENDO": DICIONÁRIOS HISTÓRICOS E ABONAÇÕES}

Nesta seção, tentaremos compreender de que modo algumas fontes podem lançar mais questões para a história da palavra. Destacamos o texto de Duarte Nunes de Leão (1606) e o Vocabulario de Raphael Bluteau ([1712-1728]) por trazerem reflexões posteriores acerca da palavra "puto". Embora compreendamos que não há uma linearidade entre o medievo ibério, e os séculos XVII e XVII da modernidade, há uma questão que nos obriga a pensar esses textos como um "fórum" acerca da interpretação dos sentidos do epíteto "puto", qual seja: a moralidade cristã. É esse elemento que instrui as explicações desses textos e que aqui vale a pena serem pensados juntos, fora da lógica 
etapista, de uma história que persegue as regularidades e lida mal com a transformação. Na observação nietzschiana, temos: “A história antiquária degenera-se justamente no instante em que a fresca vida do presente não a anima e entusiasma" (NIETZSCHE, 2003, p. 28). Não há, portanto, uma defesa de uma permanência, mas a compreensão dos papeis da moralidade da antiguidade e da reinvenção dela numa dimensão religiosa que atravessam os discursos de depreciação da relação entre homens, especialmente quando vinculados ao "papel sexual" atribuído à mulher.

De tudo que já discutimos, o que gostaríamos de colocar em evidência é o verso "daquestes putos que s'andam fodendo". É nessa passagem que podemos ver uma das primeiras ocorrências da palavra em língua portuguesa, já datadas desde o século XIII. Embora os cancioneiros que transmitem a cantiga sejam cópias posteriores, a pesquisas biográficas acerca de Pero da Ponte são assertivas em afirmar que o trovador deve ter sido galego, provavelmente atuante nas cortes de Fernando III e Afonso X.

Para entender o sentido com que se emprega a palavra puto, precisamos novamente recorrer aos versos da cantiga para entender as relações paralelísticas que podem ser inferidas. Os versos finais de cada terceto - "e trob'a eles e a seus maridos" e "daquestes putos que s'andam fodendo" trazem, em específico, a materialidade pela qual podemos afirmar que "putos" é uma anáfora "fodidos" e "seus maridos", uma espécie de hiperônimo para as práticas daqueles que "se andam fodendo". Por outras palavras, puto parece ser uma palavra que sintetiza a sintaxe sexual descrita a partir das ocorrências "eles" (os fodidos) e "maridos". Curioso é que a posição sexual ativa parece estar reconhecida a partir da palavra "marido" em decalque ao costume comum, i. e., relação entre homens e mulheres, em que o homem tem a posição de ativo. Diante disso, podemos reiterar o argumento de avaliação moral por 
meio da ideia de que putos é uma designação não só para passivos ou ativos, mas para aqueles que se relacionam com um igual.

O verso da ocorrência "puto" traz mais uma hipótese interessante, uma vez que o étimo de puto não exclusivamente está relacionado à sodomia, mas também à juventude (veremos adiante), traço que se preserva inclusive em várias línguas românicas, como o italiano e português europeu. O caso não é simples: se de fato o paralelismo e as anáforas lexicais favorecem a compreensão de puto como sodomita na cantiga, a oração adjetiva "que s'andam fodendo" pode trazer um aspecto restritivo à palavra "puto", de modo que se trataria "daquestes putos", e não necessariamente de todos ou de uma identificação de uma prática social e sexual. A questão, então, passa a ser: a oração adjetiva introduz uma restrição ou desenvolve uma explicação para o nome? A resposta mais arrojada para isso só pode ser dada com uma pesquisa quantitativa e qualitativa, procedimento que não será explorado nesta discussão. É que precisamos saber se se trata de uma introdução de informação nova, mais específica, ou um dado socialmente partilhado.

Entretanto, outra possibilidade interpretativa surge ao observarmos uma outra palavra no mesmo corpus satírico, do trovador português Martim Soares, nascido entre 1220 e 1260. Sobre ele, Lopes (2011-) afirma:

Embora não haja dados seguros sobre o seu percurso, um Martim Soares, trobador, seguramente o nosso autor, surge como testemunha num documento de 1241, uma venda feita por um Martim Garcia e sua mulher ao mosteiro de Santa Cruz. Baseado neste documento, crê Resende de Oliveira2 que Martim Soares teria sido vassalo de Martim Garcia de Parada, importante personagem da corte de D. Sancho II, cujo partido toma durante a guerra civil que conduziu à sua deposição (1245-1247). O trovador poderá, pois, segundo este investigador, tê-lo acompanhado para Castela, juntamente com o rei deposto, e por lá deve ter permanecido durante uns anos, como as suas ligações aos trovadores e jograis do círculo de Afonso X atestam. (LOPES, 2011-) 
A palavra usada por Martim Soares é putanheiro, e ela ocorre na cantiga [Nostro Senhor, com'eu ando coitado], cuja rubrica explica muito bem o contexto e a direção da sátira, a saber: “Esta outra cantiga fez a Afons'Eanes do Cotom. Foi de maldizer aposto, em que mostrava dizendo mal de si, as manhas que o outr'havia; e diz assi.". Numa paráfrase, podemos dizer que Martim Soares fez uma cantiga para o trovador Afonso Eanes do Cotom emulando a voz de Cotom e descrevendo suas "manhas", habilidades, qualidades etc., que, a rigor, são vícios de reclamam o riso. Ao lermos a estrofe a seguir:

\author{
Nostro Senhor, com'eu ando coitado \\ com estas manhas que mi quisestes dar: \\ som mui gram putanheir[o] aficado \\ e pago-me muito d'os dados jogar; \\ des $i$ ar hei mui gram sabor de morar \\ per estas ruas, vivend'apartado. (LOPES, 2011-),
}

percebemos que Soares faz com que Cotom diga da sua vida boêmia, dos prazeres da vida e de sua vocação para os prazeres da vida, tais como o sexo, o jogo etc. Ao que parece, "putanheiro" designa o perfil de quem é assíduo em zonas de prostituição, ou talvez de quem se relaciona com "putas" (prostitutas). Simões Neto (2016), ao estudar a produtividade do morfema "-eiro" numa abordagem construcional, comenta a ocorrência "putanh-eiro" e a define como uma construção de agente frequentativo, habitual, ao lado de construções como "ped-eira" (ocorrência encontrada na cantiga [Covilheira velha, se vos fezesse] de Cotom, por exemplo). Esse processo de derivação -eiro como agente habitual é bastante recorrente no Português Arcaico, fato que nos dá garantias de uma alta produtividade.

Uma breve leitura de referências lexicográficas - o autor consulta marcos lexicográficos como o Corominas e o Dicionário da Real Académia, além dos dicionários históricos da língua portuguesa e de outras línguas românicas - 
realizada por Simões Neto (2016) parece indicar que "putanh-eiro" ocorre também em espanhol putañear (ter relações sexuais com uma prostituta) e tem adjetivo correspondente em putañero e putero (homem que mantém relações sexuais com prostitutas). Assim, temos de pensar os sentidos que são produzidos a partir de puto (lat. puttus, a) e, antes de afirmar diretamente que puto significa sodomita masculino, talvez tenhamos de nos perguntar se puto não está, assim como puta ligada ao campo dos "vícios", da sexualidade, da prostituição dentro do quadro de moralidade a que os trovadores recorrem, ainda que num contexto de jogo e de diversão. Parece contribuir para isso o fato de que, na cena em que Soares maldiz apostamente Cotom, ele usa a palavra "putanheiro" que faz derivação a partir do radical put-/put(a)nh-, mas que não diz respeito à sodomia masculina, e sim ao potencial lascivo, sexual de Cotom. Assim, precisamos notar que puto e/ou putanheiro materializam a dimensão sexual, mas é o contexto e relações anafóricas estabelecida pelos paralelismos das cantigas que parecem sublinhar a sodomia masculina.

De qualquer maneira, a história da palavra puto precisa ser pensada a partir de um campo lexical mais complexo, que permitam compreender as migrações e derivas de sentido. Aqui, dada a dimensão proposta, não poderemos tratar, por exemplo, da intrigante diferença semântica entre "puta" e "puto" no período medieval. Entretanto, podemos - sem surpresas - afirmar que essas palavras são polissêmicas e que os sentidos sexuais que emergem no contexto românico são acionados por um imaginário misógino, cujos efeitos reverberam nas mulheres e em homens que, segundo o costume comum, não cumprem seu papel. Esses homens de costumes naturais incomuns são insultados a partir das mesmas marcas dos discursos misóginos. São os signos femininos que insultam os sodomitas, é no feminino que a escalada da ofensa ganha a dimensão do riso. 
Em relação às transformações de sentido dessas palavras, a Origem da Lingoa Portvgvesa, publicada em 1606, por Duarte Nunes de Leão, aponta-nos algumas informações sobre a percepção da palavra "puta" na língua portuguesa por um processo que Leão chamou de "corrupção per impropriedade de significação alhea". Esse livro emerge num momento em que Portugal estava sob dominação Espanhola, quando brios "nacionalistas" põem em ebulição discursos de defesa e de busca pelas origens do português no momento em que o Castelhano é língua corrente. A rigor, a passagem pertence ao "CAPITVLO VII", em que são apresentadas "Das muitas maneiras perque se causou a corrupção da lingoa Latina que em Hespanha fallaua na que se oje falla" (LEÃO, 1606, p. 33). Logo nas primeiras linhas, conseguimos compreender a concepção de corrupção linguística que instrui o argumento de Duarte N. de Leão, a saber:

Natural cousa he aos que se entremetem a falar algũa lingoa alhea desencaminharse das regras, \& propriedade dela, \& commetterem os vícios que chamão barbarismos solecismos, mormente quando as lingoas são mui dessemelhantes como aconteceo aos Godos, \& Vandalos, \& outros taes nascidos na Gothia, \& na Sarmacia. Vindo a Hespanha onde a lingoa latina casta \& pura que se fallaua corromperaõ, adulterando os vocábulos, \& mudandoos em outra forma. E significado diferente, \& introduzindo outros de nouo de suas terras, \& de outras gẽtes que se consigo trouxeraõ. Das quaes corrupções poremos algũs exemplos perque os lectores saberaõ muitos segredos desta lingoa, que atequi naõ entendiaõ. $\mathrm{E}$ a estimologia de muitos vocábulos que lhes abriraa os olhos para investigarem o mais. (LEÃO, 1606, p. 33-34).

Nessa perspectiva, o latim falado na Península Ibérica desde o século II a. C., muito embora estivesse em contato com as populações autóctones indoeuropeias e pré-indo-europeias (GAMA, 1995), teria permanecido casta e pura. A corrupção só teria vindo a partir da chegada de germânicos que, ao começar a falar Latim, mudaram os sentidos e as formas originais maculando, assim, a castidade romana. O léxico utilizado - "castidade", "pureza", "corrupção" - 
aciona, de modo figurativo, o discurso cristão para pensar o que hoje entendemos como mudança linguística, mas que em Leão é percebido de modo depreciativo, negativo, como uma alteração da ordem original latina. Há, portanto, uma dimensão moral que pode ser percebida nos mais diferentes exemplos ao longo do capítulo 7. De todos, que, em princípio parecem “apenas parecem" - ficar no nível do código linguístico, sem uma necessária relação com as explicações históricas, sociais e culturais, vale destacar a explicação para o termo "puta", qual seja:

Outra tal foi a corrupção da palavra, puta, que sendo vocábulo honestíssimo que quer dizer moça puríssima, \& limpa, por encobrir a fealdade do vocabulo de meretriz, ou outro tam feo, vieraõ a infamar aquelle nome, chamando puta a molher que estaa posta ao ganho, \& putaria o lugar onde ganha. (LEÃO, 1606, p. 49-51).

Nesse excerto, estão materializadas as dimensões morais implicadas na mudança promovida pelos germânicos que entraram em contato com o latim puro e casto. Ao dizer de uma palavra "vocábulo honestíssimo" ou da "fealdade" de outro como "meretriz", Leão traz uma implicação muito consistente da relação entre palavra e mundo, nesse caso o condenável mundo das práticas de prostituição, moralmente reprovável para a língua portuguesa, especialmente por sua origem latina.

Outro aspecto interessa-nos nessa passagem. A explicação eufemística para a mudança de "puta", que em latim significava "moça puríssima, \& limpa", para puta, "a molher que estaa posta ao ganho". Essa expansão semântica do termo serve muito para explicar a moralidade social que elabora essa relação entre juventude e prostituição, pois, ao idealizar a juventude como princípio de pureza e castidade, o imaginário patriarcal que organiza objetificando-a a partir de um estereótipo de uma "santidade" (pureza e limpeza). O fato é que a fantasia coisificadora que envolve a juventude (pureza) 
só pode ser construída a partir de um contexto que também moraliza a prática sexual, responsabilizando a mulher, e não o homem, por toda ruptura com esse pacto. É por isso que feio é o vocábulo "meretriz", e não "putanheiro".

Por outro lado, o eufemismo a que aludimos pode ser mais complexo ao apontar o valor que se dá à juventude na expressão do desejo pela mulher na prostituição; então, teríamos uma objetificação metonímica: a pureza, a juventude (associada à honestidade) funciona também como elemento que atrai funda o imaginário social. Tais cruzamentos fazem-nos concluir que se trata de um fetiche moral, em que estão em jogo elementos da moralidade cristã (a pureza e o pecado) e o culto à juventude. Daí, podemos ver a dimensão etária da palavra "puta" materializar os sentidos para o desejo pela castidade e pureza dentro da lógica da prostituição no contexto medieval. Assim, por fetiche moral entendemos todo imaginário que produz a erotização do corpo jovem sob o prisma da castidade, virgindade e santidade, num gesto de erotização do sublime, tanto da matéria do sagrado cristão, quanto nos temas da lírica amorosa de base na tradição clássica.

Se olharmos os textos em que as mulheres são alvo das sátiras, o que encontraremos é exatamente o tema da velhice associado à impureza, sensualidade, voluptuosidade, indecência e lubricidade. Acerca disso, não podemos deixar de mencionar as inúmeras cantigas satíricas e de maldizer dos trovadores galego-portugueses que trazem como elementos tópicos da injúria a velhice como elemento de depravação moral pelo comportamento sexual. É este o caso da "velha fududancua!" da cantiga [O meu senhor o bispo, na Redondela, um dia,] de Airas Nunes; da dona fea, velha e sandia!, da cantiga [Ai dona fea, fostes-vos queixar,], de João Garcia de Guilhade; ou da cantiga de Afonso X, que, para nós, traz o ambiente mais qualificado para compreendermos o jogo moral que envolve as questões etárias, castidade e corpo. Destacamos em especial a estrofe seguinte, da edição de Lopes (2011-): 


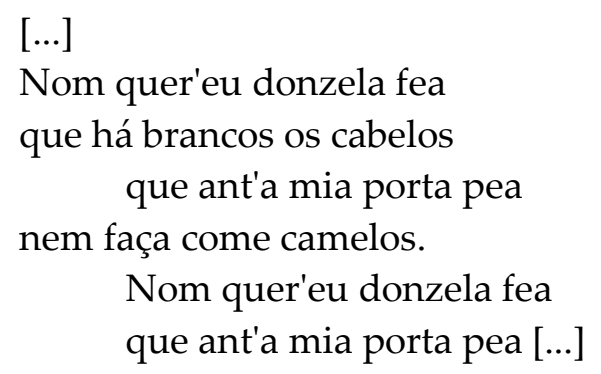

Nesse trecho, o rei trovador satiriza, em primeira pessoa, o perfil de uma donzela, ou melhor, daquela que ele (e os homens de modo mais geral) não quer por causa das características físicas. Vale ressaltar que não se trata apenas de uma questão meramente estética, "de gosto", mas sim dos significados morais para a mulher desse corpo, já que, nesse contexto, não podemos deixar de dizer das implicações morais da idade, do cabelo, da cor da pele, isto é, da beleza ou da feiúra, do humano e do desumano.

É sob esse prisma que a "donzela fea" é satirizada pelos "cabelos brancos", por peidar, por ser "negra come carvom" e por cheirar como "camelos" em época de cio, como lê Videira Lopes (2011-). Tudo isso constitui matéria para o riso. A dimensão da lascívia e da velhice da "donzela", atreladas à cor da pele, funciona de maneira inversamente proporcional à imagem da donzela idealizada pelo imaginário cortês: a pele alva como signo da pureza e da honestidade, e, por isso mesmo, da objetificação racializada do erotismo.

Por mais que o termo raça tenha de ser contextualizado para o período, tal como "homossexualidade"/sodomia masculina e outros que parecem avançar da contemporaneidade para o passado medieval, precisamos entender que o uso da ideia de raça está sendo utilizado aqui para compreender o mecanismo social do medievo ibérico que reconhece a cor da pele como um elemento de distinção, de produção de hierarquia e de valores, que, inevitavelmente, são capazes de redundar em discursos de violência, de desumanização. De outro lado, não estamos afirmando que a cantiga foi 
imediatamente responsável por isso, isso tornaria mais simples o problema localizando o problema no tempo e no espaço. Ao contrário, a cantiga é parte de algo muito maior e ainda mais antigo. Antes, afirmamos que a tópica da feiúra negra descrita como visceralmente sexual é um elemento que está amplamente estruturando as relações e a violência dentro desse imaginário do amor, da beleza e da moral.

Parêntesis feito para pensar a palavra "puta", gerada pela necessidade de compreender "putanheiro" (agente frequentador) e, por sua vez, "puteiro" (local frequentado), recorremos, doravante, ao Vocabulario Portuguez e latino, de Raphael Bluteau, uma obra lexicográfica de teor enciclopédico, com cerca de 55 epítetos que variam entre anatomia, arquitetura, astronomia, botânica e música, física, teologia, zoologia. No verbete "puta", observamos a indicação ao texto de Duarte Leão, cujo argumento a que já nos referimos é seguido. Não por acaso, é-nos necessário mencionar que o Vocabulario foi escrito por um religioso cristão e que o texto está estruturado por essa visão de mundo, mas não apenas por ela, uma vez que Bluteau recorre ao mundo latino para propor "derivações" para a palavra "puta", tais como Putêre (cheirar mal), ou uma "antiphrasis de Putus, a, um,", além de referências ao mundo latino como forma de apresentar as possibilidades de sentido e dos usos da palavra. O excerto a seguir ilustra bem: “Os antigos Romanos chamavão às putas, Lobas, donde veyo a palavra Lupanar, isto he, Casa da mulher deshonesta; \& neste sentido querem algũs que Romulo, \& Remo foraõ criados por huma loba, isto he mulher publica.", além disso, segue utilizando referência bíblicas, como a do capítulo 17 do "Apocalypse", em que se representa a meretriz com um escrito na testa: Babylon (a grande Babilônia) (BLUTEAU, [1712-1728], p. 837), “a mãe das prostituições e das abominações da terra". Essa fusão entre o mundo antigo grego e greco-romano com o cristianismo é muito fecunda no período medieval e permanece, de modo não linear, no imaginário ocidental, em múltiplas metáforas. 
Essa estrutura argumental que sintetiza o mundo antigo com o cristão medieval está também no verbete "puto", objeto de nossa reflexão:

PUTO. Agente, ou paciente no pecado nefando. Cicero chama Puer meritorius ao rapaz, que por dinheyro se postitue a estas torpezas; em outro lugar chamalhe com palavra Grega Catamitus i. Masc. Cinaedus, i. Masc. Em Aulo-Gelio tem quase a mesma significação. Nihil interest (diz este Author) quibus membris cinaedi sitis, posterioribus an prioribus. (BLUTEAU, [17121728], p. 837).

Para "puto", Bluteau encontra imediatamente uma definição da relação entre homens como pecado, de tal modo que é possível afirmar que existe uma implicação imediata entre relação sexual entre homens como "pecado nefando". Quer sejam "agentes", quer sejam "pacientes" - revelando a importância da sintaxe da performance sexual para o tema - estão em xeque questões relativas à juventude e à prostituição. As abonações para textos em latim e em grego funcionam como prova argumental para a definição da cabeça do verbete, por isso Cícero em dois momentos: "puer meritorius" (moço que ganha com prostituição), Catamitus, i/cinaedus, $i$ (sodomita), mas é citando Aulo Gélio, nas Noites Áticas, 3.5, que a compreensão de puto é decalcada, a saber: "Nihil interest (diz este Author) quibus membris cinaedi sitis, posterioribus an prioribus", numa tradução possível: "não interessa com que parte do corpo você seja um sodomita, de trás ou de frente".

Desse modo, por mais que a proposta de definição de Bluteau possa oferecer questionamentos contemporâneos diante do modus operandi de sua lexicografia, é fundamental compreender que tais verbetes servem como fonte para compreensão moral das questões relacionadas à sodomia e que elas se filiam a um repertório historicamente consolidado pela moral cristã. Por isso, por mais que não possamos aproximar temporalmente o Vocabulario da cantiga medieval galego-portuguesa, usando a obra de referência como recurso 
metalinguístico para explicação da cantiga de Pero da Ponte, vale compreender como o imaginário acerca da sodomia se estruturou a partir das noções morais contra a prostituição, sob o signo da juventude.

Assim, é possível manter o argumento que lançamos acerca da palavra puto que ocorre no verso nono da cantiga de Pero da Ponte. Acreditamos que puto é uma expressão genérica para a sodomia, quer seja para "fodidos" (paciente), quer seja para "seus maridos" (agente). Desse modo, ao reafirmar que continuará a fazer "cobras e sões" sobre os "putos que s'andam fodendo", com a partícula reflexiva se reiterando a prática sodomítica, temos de defender que a cantiga é tanto de sátira a anônimos, datados e localizados especificamente, mas também está amplamente baseada, e por isso mesmo, num esquema valorativo de natureza moral fundado a partir das sínteses do mundo antigo e cristão medieval, dentro, aliás, do que propõe Auerbach em seu célebre Mimesis (2007).

\section{CONSIDERAÇÕES PROVISÓRIAS}

A história de uma palavra não pode ser contada exclusivamente a partir da análise etimológica. Aliás, tal abordagem é uma das possibilidades que podemos acionar para entender as coordenadas culturais, políticas e sociais que atravessam os usos linguísticos na história. Por isso, compreender de modo mais estratégico os textos que transmitiram as ocorrências lexicais que pretendemos historicizar é uma forma de redirecionar a experiência da crítica filológica de textos para uma "história da palavra". Muitas vezes, a frieza das abonações dos verbetes de glossários ou obras lexicográficas mais gerais, embora atentem à necessidade de leitura do texto e a objetivos mais imediatos, não explora as redes de relações semânticas que o contexto de ocorrência traz, nem as implicações do gênero para o entendimento do texto em que a palavra 
está, tampouco investiga outros textos correlatos do período de modo a testar a amplitude das hipóteses lançadas.

Longe de definir um método rigoroso que traga "à luz" a história da palavra "puto", preferimos explorar outras metáforas que não esta que foi eleita pela racionalidade cientificista, cujo modo de compreender tolheu ou privilegiou alguns sentidos em detrimento de outros. Ao contrário, levantamos mais inferências. Em lugar da transparência, opacidade. Assim, a partir da leitura de diversas fontes, investigamos de que forma, potencialmente, podemos compreender "puto" não só como "sodomita", mas também entender os significados sociais do corpo jovem, a sintaxe espacial das performances sexuais de "agente" e "paciente" na relação entre homens, a dimensão da prostituição. Tais elementos estão presentes em vários textos da tradição antiga grega e greco-latina e parecem permanecer indiciária ou subjacentemente nos movimentos de sentido produzidos pelos usos de "puto" no período medieval.

Se ainda hoje permanecem sentidos de puto como "moços", "meninos", em diversas línguas românicas, que é uma acepção documentada também em latim, isso serve para compreendermos que a acepção para "sodomita" ou "prostituto" não necessariamente correspondeu a uma mudança; mas a uma expansão do sentido. Por isso, os "putos" de Pero da Ponte articulam a dimensão da sodomia masculina, e também dão espaço para pensar os significados sociais das performances sexuais ou dos "consórcios afetivos", para usar uma expressão de Sodré (2007) entre os "fodidos" (pacientes) e "seus maridos" (agentes).

De modo diferente, Carlos Callón, que também lê a cantiga de Pero da Ponte em sua tese de doutoramento, o termo "puto" não pode ser relacionado à prostituição, pelo fato de não haver menção evidente a questões monetárias. Ele afirma: 
Tampouco hai nesa composición ningún elemento que nos leve a pensar nunha prostitución estabelecida. Non existe aí ningún matiz monetario, senón que se fala de varóns que teñen por propia vontade esas prácticas sexuais e que mesmo tentarían ter ese tipo de prácticas cun home que manifesta o seu distanciamento deles e a súa autoidentificación como "fadimalho" (v. 1). (CALLÓN, 2017, p. 357)

Para explorarmos melhor essa história, cremos que seja importante pensar a história da palavra "puto" em relação com "puta" e outras palavras derivadas para que entendamos mais matizes de sentido que estão em interessam para a produção e deslocamentos de sentidos das palavras. Porém, essa demanda precisará de outra oportunidade de maior fôlego investigativo e de articulações ainda mais interdisciplinares. Por ora, temos os sentidos de "puto" compreendidos entre uma expressão de uma categoria de relação entre homens, a juventude, a objetificação do corpo e o pensamento moral cristão apropriado como elemento fundamental da operação do desejo no discurso da prostituição.

\section{REFERÊNCIAS}

ALFONSO X. Las siete partidas. Edição fac-similada da edição salmantina de 1555, glosada por Gregorio Lopez e impressa por Andrea de Portonariis. Madrid: Boletín Oficial del Estado, 1974. 3 v.

ALFONSO X. Las siete partidas. Translation by Samuel Parsons Scott. Edition by Robert I. Burns. Pennsylvania: University of Pennsylvania, 2001. v. II.

ALFONSO X. Las siete partidas: antología. Selección de Francisco López Estrada y María Teresa López García-Berdoy. Madrid: Castalia, 1992.

AUERBACH, Erich. Mimesis: a representação da realidade na literatura ocidental. São Paulo: Perspectiva, 2007.

BLUTEAU, Rafael. Vocabulario portuguez, e latino, aulico, anatomico, architectonico, bellico, botanico ... : autorizado com exemplos dos melhores escritores portuguezes, e latinos; e offerecido a El Rey de Portugal D. Joaõ V. Coimbra, Collegio das Artes da Companhia de Jesu : Lisboa, Officina de Pascoal da Sylva, 1712-1728. 8 v; 2 Suplementos. 
CALLÓN, Carlos. As relacións sexoafectivas intermasculinas e interfemininas no trobadorismo galego. 2017. 468f. Tese (Doutorado em Letras) - Programa Oficial de Doutoramento em Estudos Lingüísticos e Literarios do Galego e do Portugués, Universidade da Coruña.

FOUCAULT, Michel. História da Sexualidade I:A vontade de saber. Tradução de Maria Thereza da Costa Albuquerque e J. A. Guilhon Albuquerque. Rio de Janeiro: Edições Graal, 1988.

GAMA, Nilton Vasco da. A variação do latim e a formação das línguas românicas. Quinto Império, Salvador, v. 5, p. 39-51, Seg. sem. 1995.

KILOMBA, Grada. Memórias da Plantação: episódios de racismo quotidiano. Lisboa: Orfeu Negro, 2019.

LAPA, Manuel Rodrigues (Ed.). Cantigas d'escarnho e maldizer dos cancioneiros medievais galego-portugueses. 3. ed. Lisboa: João Sá da Costa, 1995.

LOPES, Graça Videira (Ed.). Cantigas de escárnio e maldizer dos trovadores e jograis galegoportugueses. Lisboa: Estampa, 2002.

LOPES, Graça Videira. A sátira nos cancioneiros medievais galego-portugueses. Lisboa: Estampa, 1994.

LOPES, Graça Videira; FERREIRA, Manuel Pedro et al. Cantigas Medievais Galego Portuguesas [base de dados online]. Lisboa: Instituto de Estudos Medievais, FCSH/NOVA, 2011-. Disponível em: [http://cantigas.fcsh.unl.pt]. Acesso em: 31 mar. 2021.

MADERO, Marta. Manos violentas, palabras vedadas: la injuria en castilla y en León (siglos XIII-XV). Madrid: Taurus, 1992.

NIETZSCHE, Friedrich Wilhelm. Segunda consideração intempestiva: da utilidade e desvantagens para vida. Tradução Marco Antônio Casanova. Rio de Janeiro: Relume Dumará, 2003.

NUNES DO LEÃO, Duarte. Origem, e Orthografia da Lingoa Portugvesa. Lisboa: Pedro Crasbeeck, 1606.

SACRAMENTO DE SOUZA, Arivaldo. A Representação das relações entre homens nas cantigas de escárnio e maldizer galego-portuguesas. 2008. 153f. Dissertação (Mestrado em Letras e Linguística) - Universidade Federal da Bahia. Instituto de Letras, Salvador, 2008.

SIMÕES NETO, Natival Almeida. Um enfoque construcional sobre as formações X-eir-: da origem latina ao português arcaico. 2016. Dissertação (Mestrado em Língua e Cultura) - Universidade Federal da Bahia, Instituto de Letras, Salvador.

SODRÉ, Paulo Roberto. A sodomia no "jugar de palabras" de Estevão da Guarda. Aletria: Revista de Estudos Literários, Belo Horizonte, n. 13, p. 125-132, 2006 a.

SODRÉ, Paulo Roberto. Ainda sobre a sodomia na sátira galego-portuguesa: a propósito da cantiga "Do que eu Quígi, per sabedoria”, de Estêvão da Guarda. Revista do CESP, Belo Horizonte, v. 27, n. 37, jan.-jun. 2007. Disponível em: 
[http://www.periodicos.letras.ufmg.br/index.php/cesp/article/viewFile/6601/5601]. Acesso em: 31 mar. 2021.

SODRÉ, Paulo Roberto. Os homens entre si: os "fodidos e seus maridos" nas cantigas de Pero da Ponte, séc. XIII. In: LOPES, Denilson et al. Imagem e diversidade: estudos da homocultura. São Paulo: Nojosa, 2004. p. 246-253.

SODRÉ, Paulo Roberto. Pero da Ponte e os trebelhos de Tisso Pérez: entre o retraer e o difamar. In: _.. (Org.). Multiteorias: correntes críticas, culturalismo, transdisciplinaridade. Vitória: Ufes/Programa de Pós-Graduação em Letras/Mestrado em Estudos Literários, 2006b. Disponível em: [www.ufes.br/ mlb/multiteorias/]. Acesso em 31 mar. 2021.

Nota do editor:

Artigo submetido para avaliação em: 31 de março de 2021.

Aprovado em sistema duplo cego em: 18 de maio de 2021. 